\title{
Acute Pseudogout Arthritis in a Patient Using Diuretics
}

\author{
Fatih AKKOÇ, Canan TIKIZ, Özgür AKGÜL \\ Department of Physical Medicine and Rehabilitation, Medical Faculty of Celal Bayar University, Manisa, Turkey
}

Calcium pyrophosphate deposition disease (CPDD) is a crystal arthropathy caused by the deposition of calcium pyrophosphate dehydrate in and around joints, particularly in articular cartilage and fibrocartilage. The 'Pseudogout syndrome' was first described by Kohn et al. ${ }^{1}$ in 1962 and accurately depicts acute attacks of synovitis induced by calcium pyrophosphate dehydrate crystals. In this article, we report an elderly patient with acute pseudogout arthritis who had been on loop diuretic treatment for 10 years. The aim of this report is to draw attention to imaging techniques for diagnosis and also highlight the factors that trigger CPDD in elderly patients.

A 79-year-old female patient was admitted to our clinic for knee pain. Patient has had knee pain for years which worsened recently. She denied any swelling, redness, or night pain. On physical examination, all findings were normal except for rough crepitation of knees. She had chronic renal failure and coronary artery disease. Medical treatment included furosemide $40 \mathrm{mg} /$ day, clopidogrel $75 \mathrm{mg} /$ day, and pantoprazole $40 \mathrm{mg} /$ day.

She was hospitalized and osteoarthritis of the knee was diagnosed. After three days of hospitalization, pain and swelling occurred on her left wrist. The laboratory findings were as follows: uric acid: $9.9 \mathrm{mg} / \mathrm{dL}, \mathrm{C}$-reactive protein: $167 \mathrm{mg} / \mathrm{L}$, white blood cells: $12.610^{3} / \mu \mathrm{L}$, creatinine: $1.4 \mathrm{mg} / \mathrm{dL}$, and serum magnesium:
$1.3 \mathrm{mg} / \mathrm{dL}$ (normal $>1.8 \mathrm{mg} / \mathrm{dL}$ ). On wrist $\mathrm{X}$-ray, there were cystic lesions on carpal and metacarpal bones, and calcification at triangular cartilage localization (Figure 1). Musculoskeletal ultrasonography (USG) of the wrist joint was performed. Effusion was detected at radiocarpal joint on gray scale USG and active synovitis were detected on power Doppler USG. CPDD of the wrist was diagnosed. Prednisolone $5 \mathrm{mg} /$ day and oral magnesium were initiated and furosemide was stopped. Thirty milligrams triamcinolone acetonide was injected into the radiocarpal joint with USG guidance. On the third day of treatment, swelling regressed and pain resolved.

Here, we presented a case with CPDD arthritis. In elderly patients, calcium pyrophosphate

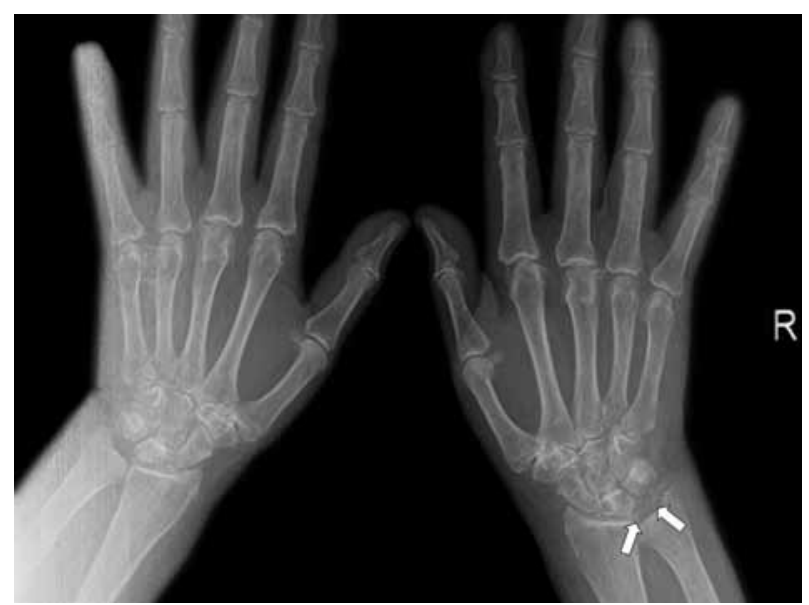

Figure 1. Arrows show calcification. 
dehydrate is a common finding in many fibrocartilages and hyaline articular cartilages of larger joints, tendons, and soft tissues. The age is the most important risk factor for CPDD. Other factors are previous damages to joints such as osteoarthritis, end-stage kidney disease, hyperparathyroidism, hemochromatosis, hypophosphatasia, hypomagnesemia, aging, and medications including diuretics. ${ }^{2}$

The association between CPDD and chronic use of diuretics has been reported; however, to our knowledge, no association has been shown between CPDD and chronic use of antihypertensive drugs. Increased urinary magnesium loss due to thiazides and loop diuretics inhibit magnesium re-absorption by the renal tubules. ${ }^{3}$ Magnesium is known to be one of the cofactors of many pyrophosphatases and there is a direct relationship between the solubility of calcium pyrophosphatase and serum concentration of magnesium. Hypomagnesemia might produce CPPD due to the pyrophosphates' enzymatic activity dependence on magnesium ions. Precipitation of these calcium pyrophosphate crystals in the joint produces episodes of pseudogout. $^{4}$

Triggering factors of CPPD, such as use of diuretics and hypomagnesemia, should always be considered. Magnesium should be added to antiinflammatory treatment and the underlying condition of hypomagnesemia should be detected and treated.

\section{Declaration of conflicting interests}

The authors declared no conflicts of interest with respect to the authorship and/or publication of this article.

\section{Funding}

The authors received no financial support for the research and/or authorship of this article.

\section{REFERENCES}

1. Kohn NN, Hughes RE, Mccarty DJ Jr, Faires JS. The significance of calcium phosphate crystals in the synovial fluid of arthritic patients: the "pseudogout syndrome". II. Identification of crystals. Ann Intern Med 1962;56:738-45.

2. Terkeltaub R. Imaging joints for calcium pyrophosphate crystal deposition: a knock to the knees. Arthritis Res Ther 2012;14:128.

3. Richette P, Bardin T, Doherty M. An update on the epidemiology of calcium pyrophosphate dihydrate crystal deposition disease. Rheumatology (Oxford) 2009;48:711-5.

4. González Domínguez J, Escudero Contreras A, Pérez Guijo V, Martínez Sánchez FG, Caracuel Ruiz MÁ, Collantes Estévez E. Chondrocalcinosis and hypomagnesemia: clinical and radiological progression. Reumatol Clin 2008;4:37-9. [Abstract] 